

\title{
ANALISIS TINGKAT KESEGARAN JASMANI PESERTA DIDIK DITINJAU DARI SARANA PRASARANA PENDIDIKAN JASMANI \\ DI SEKOLAH DASAR NEGERI MARTAPURA KABUPATEN BANJAR
}

\author{
Muhammad Miftah Effendi, M. Kusaini, Abd. Hamid \\ Program Studi Pendidikan Jasmani JPOK FKIP \\ Universitas Lambung Mangkurat Banjar \\ miftaheffendi97@gmail.com
}

\begin{abstract}
Abstrak
Penelitian ini bertujuan agar tahu bagaimana tingkat kesegaran jasmani seorang peserta didik yang ditinjau dari sarana prasarana pedidikan jasmani di SDN Martapura Kabupaten Banjar. Metodenya ialah metode kombinasi (mixed method) dengan tekhnik pengambilan data secara tes mengukur apa yang perlu diukur dan observasi. Dan juga untuk populasinya berjumlah sebanyak 226 orang peserta didik, tetapi yang diambil jadi sampel cuman 32 orang peserta didik yang usianya dari $10-12$ tahun, terdiri dari Sekolah Dasar Negeri Keramat, Sekolah Dasar Negeri Sungai Batang 1 dan Sekolah Dasar Negeri Melayu Tengah Martapura Kabupaten Banjar.

Hasil akhir dari penelitian ini didapat dari Sekolah Dasar Negeri Keramat dengan jumlah sampel 17 orang peserta didik, 2 orang peserta didik $(11,76 \%)$ klasifikasi sedang (S), 9 orang peserta didik $(52,94 \%)$ klasifikasi kurang (K) dan 6 orang perserta didik $(35,50 \%)$.klasifikasi kurang sekali (KS). Sekolah Dasar Negeri Sungai Batang 1 jumlah sampel 6 orang peserta didik, 1 orang peserta didik (16,67\%), klasifikasi sedang (S), 2 orang peserta didik $(33,33 \%)$ klasifikasi kurang $(\mathrm{K}), 3$ orang peserta didik $(50,00 \%)$ kalsifikasi kurang sekali (KS). Sekolah Dasar Negeri Melayu Tengah jumlah sampel 9 orang peserta didik, 1 orang peserta didik $(11,11 \%)$ klasifikasi sedang $(\mathrm{S}), 5$ orang peserta didik $(55,56 \%)$ klasifikasi kurang (K), 3 orang peserta didik $(33,33 \%)$ kalsifikasi kurang sekali (KS).
\end{abstract}

Kata Kunci: Analisis, Tingkat, Kesegaran Jasmani sarana dan prasarana peserta didik sekolah dasar

\begin{abstract}
This study aims to know how the level of physical fitness of a student in terms of physical education facilities in SDN Martapura, Banjar Regency. The method is a combination method (mixed method) with data collection techniques by measuring what needs to be measured and observed. And also for its population totaling 226 students, but only 32 samples were taken from 10 - 12 years old, consisting of Keramat State Elementary School, Sungai Batang 1 State Elementary School and Central Malay State Primary School Martapura Regency Banjar.

The final results of this study were obtained from the Keramat State Primary School with a sample of 17 students, 2 students (11.76\%) moderate classification (S), 9 students (52.94\%) less classification (K) and 6 students (35.50\%), very poor classification (KS). Sungai Batang State Elementary School 1 sample size is 6 students, 1 student (16.67\%), medium classification (S), 2 students (33.33\%) poor classification (K), 3 students $(50.00 \%)$ very less calcification (KS). Central Malay State Elementary School
\end{abstract}


sample number 9 students, 1 student (11.11\%) classification is medium (S), 5 students $(55.56 \%)$ classification is less $(\mathrm{K}), 3$ students $(33), 33 \%)$ poorly calcified (KS).

Keywords: Analysis, Level, Physical Freshness of facilities and infrastructure of elementary school students

\section{PENDAHULUAN}

Olahraga merupakan suatu bentuk aktivitas/kegiatan yang dilakukan untuk kesehatan tubuh dan juga menjadi bugar. Di dalam berolahraga itu sangat erat kaitannya dengan kehidupan manusia sehari-harinya, oleh sebab itu kehidupan manusia ada dua aspek yang perlu dipenuhi, yaitu jasmani dan rohani yang tidak dapat juga dipisahkan oleh manusia, maka dari itulah olahraga sangat penting untuk tubuh seorang makhluk hidup. Olahraga didalam pendidikan sekolah itu dinamakan pendidikan jasmani yang merupakan bagian yang harus dilakukan didalam lingkungan sekolah selain untuk kesehatan juga bisa untuk berprestasi seorang peserta didik karna lewat sekolahan tersebut banyak sekali kejuaraan cabang olahraga yang dipertandingkan dan juga pendidikan jasmani di sekolah bukan hanya itu saja juga bisa membuat seorang peserta didik menjadi konsentrasi dalam belajar yang lain karna tubuh dalam keadaan gerak, makanya berolahraga itu sangat penting didalam lingkungan sekolah/pendidikan.

Pentingnya menjaga kesegaran jasmani bagi anak usia dini atau disebut anak usia sekolah antaranya juga dapat membantu meningkatkan kemampuan organ tubuh, yaitu pikiran, jiwa sosial, emosional, sportivitas, dan semangat dalam berkompetisi dalam berbagai cabor. Beberapa penelitian juga menyebutkan bahwa sanya kesegaran jasmani ini sangat erat memiliki korelasi positif dengan prestasi akedemis. Agar tercapai keterampilan ini semua tergantung oleh seorang guru dalam memberikan pembelajaran buat peserta didiknya baik itu dari bentuk latihan ataupun dari segi materi dengan unik, kreatif serta menyenangkan biar anak didik tersebut tidak merasakan kebosanan dalam belajar. Penunjang dalam pembelajaran tersebut juga sangat perlu oleh sekolah menyediakan sarana prasarana yang bisa digunakan karna ini juga sangat berpengaruh oleh pembelajaran itu sendiri selain ketingkatan kesegaran jasmaninya kurang juga membuat anak kurang bergerak maka dari itu sangat diperlukan guru yang banyak memiliki rancanga pembelajaran yang unik dan kreatif.

Dalam bentuk hal semacam ini sangat perlu pengadaan sarana prasarana yang pas dengan peserta didik disekolah tersebut, misalnya dengan menyediakan bola-bola yang banyak walaupun lapangan tidak begitu luas akan tetapi banyak alat seperti itu maka anak akan bergerak semua dengan masing-masing mendapatkan bola tersebut tanpa melakukan antri yag panjang dan jua bergerak sangat minim dalam praktek pembelajaran penjas. Akan tetapi lapanngan padahal sangat diperlukan sekali biar anak didik tersebut bisa bermian dan bergerak sebebasnya dengan semua ini akan memungkinkan sangat membantu tercapainya prestasi belajar disekolah ataupun membuat kesegaran jasmani yang baik.

Dari uraian tersebut, maka peneliti tertarik untuk melakukan penelitian tentang tingkat kesegaran jasmani yang ditinjau dari sarana prasarananya pendidikan jasmani peserta didik Sekolah Dasar Negeri (SDN) Kabupaten Banjar yang diambil sebagai sampel yaitu Sekolah Dasar Negeri Keramat, Sekolah Dasar Negeri Sungai Batang 1 dan Sekolah Dasar Negeri Melayu Tengah. 


\section{METODE PENELITIAN}

Metode penelitian yang digunakan ialah dengan metode penelitian kombinasi (Mixed Methods). Menurut Sugiyono (2015:21) bahwa, Metode penelitian kombinasi (mixed methods) adalah suatu metode penelitian yang mengkombinasikan atau menggabungkan antara metode penelitian kuantitatif dan metode kualitatif untuk digunakan secara bersama-sama dalam suatu kegiatan penelitian sehingga diperoleh data yang lebih komprehensif, valid, reliabel dan objektif.

\section{Populasi dan Sampel Penelitian}

Populasi dan sampel penelitian ini adalah peserta didik SDN Kabupaten Banjar yang berusia 10-12 tahun. Peneliti mengambil 3 sekolah sebagai sampel yaitu Sekolah Dasar Negeri Keramat Kabupaten Banjar dengan jumlah populasi 92 orang dan yang menjadi sampel 17 peserta didik. Sekolah Dasar Negeri Sungai Batang 1 Martapura Kabupaten Banjar jumlah populasi 47 peserta didik dan yang menjadi sampel 6 peserta didik. Sekolah Dasar Negeri Melayu Tengah Kabupaten Banjar jumlah populasi 87 peserta didik dan sampel 9 peserta didik. Secara keseluruhan populasi berjumlah 226 orang peserta didik dan yang menjadi sampel berdasarkan usia 10-12 tahun berjumlah 32 orang peserta didik.

\section{Tempat dan Waktu Penelitian}

Pengambilan/pengukuran data dilakukan pada hari selasa dan rabu, pada tanggal 09 dan 10 juli 2019, bertepat dikampus JPOK FKIP ULM Banjarbaru dengan waktu dari jam 7.30 Wita sampai dengan selesai dilaksanakannya.

\section{Instrumen Penelitian}

Instrumen yang dipergunakan ini ialah:

1. Untuk mengukur analisis tingkat kesegaran jasmani menggunakan tes Kesegaran Jasmani Indonesia untuk Anak Usia 10 -12 Tahun (Kemendiknas, 2010:5-15).

2. Instrumen untuk mengukur ketersediaan sarana prasarana dengan observasi, wawancara, dan dokumentasi.

\section{Teknik Pengumpulan Data}

Data yang diperlukan yaitu tingkat kesegaran ditinjau dari sarana prasarana. Adapun teknik pengumpulan data yang akan dilakukan ditempuh dengan beberapa tahapan, yaitu:

1. Tahap Persiapan:

a. Permohonan penunjukan Dosen Pembimbing I dan II.

b. Permohonan izin kepada Ketua JPOK FKIP ULM Banjarbaru.

c. Permohonan izin penelitian kepada Kepala Dinas Pendidikan Kabupaten Banjar.

d. Permohonan izin penelitian kepada Kepala Sekolah.

e. Permohonan peminjaman alat pendukung penelitian.

f. Menyiapkan formulir tes dan pengukuran.

g. Mempersiapkan petugas tes.

h. Undangan penelitian kepada Pembimbing I dan II.

2. Tahap Pelaksanaan:

Tes dan pengukuran yang dilakukan berupa TKJI yang anak usia 10-12 tahun yaitu:
a. Tes lari cepat 40 meter
b. Tes Gantung Siku Tekuk 60 detik
c. Tes Baring Duduk 30 detik
d. Tes Loncat Tegak
e. Tes Lari 600 meter 


\section{PEMBAHASAN}

Berdasarkan hasil penelitian dan data-data yang telah diuraikan diatas, maka secara umum tingkat kesegaran jasmani peserta didik di Sekolah Dasar Negeri Martapura Kabupaten Banjar yaitu Sekolah Dasar Negeri Keramat dengan jumlah sampel 17 orang peserta didik, 2 orang peserta didik $(11,76 \%)$ klasifikasi sedang (S), 9 orang peserta didik $(52,94 \%)$ klasifikasi kurang (K) dan 6 orang perserta didik (35,50\%).klasifikasi kurang sekali (KS)

Sekolah Dasar Negeri Sungai Batang 1 jumlah sampel 6 orang peserta didik, 1 orang peserta didik (16,67\%), klasifikasi sedang (S), 2 orang peserta didik $(33,33 \%)$ klasifikasi kurang (K), 3 orang peserta didik $(50,00 \%)$ kalsifikasi kurang sekali (KS).

Sekolah Dasar Negeri Melayu Tengah jumlah sampel 9 orang peserta didik, 1 orang peserta didik $(11,11 \%)$ klasifikasi sedang (S), 5 orang peserta didik $(55,56 \%)$ klasifikasi kurang (K), 3 orang peserta didik (33,33\%) kalsifikasi kurang sekali (KS).

Tabel 1. Hasil Tes Kesegaran Jasmani Indonesia

\begin{tabular}{|c|c|c|c|c|}
\hline \multirow{2}{*}{$\begin{array}{c}\text { Klasifik } \\
\text { asi }\end{array}$} & \multicolumn{3}{|c|}{ Nama Sekolah } & \multirow{7}{*}{ Total } \\
\hline & SDN Keramat & $\begin{array}{c}\text { SDN Sungai } \\
\text { Batang } 1\end{array}$ & $\begin{array}{l}\text { SDN Melayu } \\
\text { Tengah }\end{array}$ & \\
\hline BS & $0(0 \%)$ & $0(0 \%)$ & $0(0 \%)$ & \\
\hline $\mathrm{B}$ & $0(0 \%)$ & $0(0 \%)$ & $0(0 \%)$ & \\
\hline $\mathrm{S}$ & $2(12 \%)$ & $1(17 \%)$ & $1(11 \%)$ & \\
\hline $\mathrm{K}$ & $9(53 \%)$ & $2(33 \%)$ & $5(55 \%)$ & \\
\hline KS & $6(35 \%)$ & $3(50 \%)$ & $3(33 \%)$ & \\
\hline Jumlah & 17 & 6 & 9 & 32 \\
\hline
\end{tabular}

Dari hasil tersebut masih banyak peserta didik yang tingkat kesegarannya berada pada klasifikasi sedang (S), kurang (K) dan yang kurang sekali (KS). Hal ini biasanya disebabkan oleh:

1. Instrumen tes yang sangat berat bagi peserta didik rentan usianya, sehingga peserta didik tidak mampu melaksanakan dengan maksimal dan terkesan seadanya.

2. Peserta didik kurang melakukan latihan fisik, karena waktu banyak terisi dengan mengikuti pelajaran di sekolah dan aktivitas di luar sekolah digunakan untuk membantu pekerjaan rumah.

3. Peserta didik belum pernah melakukan tes kesegaran jasmani sehingga mengikuti tes dengan seadanya.

Kelengkapan sarana prasarana olahraga di Sekolah Dasar Negeri Martapura belum sesuai dengan standar minimum sarana prasarana SD yang sudah ditentukan oleh permendiknas no 24 tahun 2007 dengan rata-rata masih kurang untuk dapat dilaksanakannya kegiatan pembelajaran pendidikan jasmani, olahraga dan kesehatan.

Oleh sebab itu bisa dilihat di SDN Keramat, SDN Sungai Batang 1 dan SDN Melayu Tengah Martapura Kabupaten Banjar semuanya tidak ada yang memiliki lapangan olahraga bola voli, sepak bola, bola basket, bulu tangkis dengan hanya memanfaatkan halaman disekitar sekolah sebagai tempat untuk proses kegiatan pembelajaran penjas, dan jika air pasang dan musim hujan maka kegiatan pembelajaran penjas cuman bisa dilakukan didalam ruang kelas dengan memberi materi.

Tersedianya bola voli di SDN keramat memiliki cuman 4 buah bola saja $(66,66 \%)$ dengan kategori cukup, SDN Sungai Batang 1 dan SDN Melayu Tengah cuman memiliki 
1 buah bola saja $(16,67 \%)$ dengan kategori kurang. Untuk tersedinya bola sepak bola di SDN Keramat dengan 4 buah bola (66,66 \%) dengan kategori cukup, SDN Sungai Batang 1 dengan 3 buah bola $(50,00 \%)$ dengan kategori cukup dan SDN Melayu Tengah dengan 1 buah bola $(16,66 \%)$ dengan kategori kurang. Untuk tersedinya bola basket di SDN Keramat tidak memiliki apa-apa (0\%), SDN Sungai Batang 1 dengan 2 buah bola $(33,33 \%)$ dengan kategori kurang dan SDN Melayu Tengah tidak memiliki (0\%). Untuk tersedinya bola bulu tangkis di SDN Keramat dengan 48 buah bola (800\%) dengan kategori baik, SDN Sungai Batang 1 dengan 12 buah bola (200\%) dengan kategori baik dan SDN Melayu Tengah tidak memiliki bola (0\%). Untuk tersedinya bola kasti di SDN Keramat dengan 20 buah bola $(333,33 \%)$ dengan kategori baik, SDN Sungai Batang 1 dengan 2 buah bola $(33,33 \%)$ dengan ketegori kurang dan SDN Melayu Tengah tidak memiliki bola $(0 \%)$.

Tersedianya net bola voli di SDN Keramat dengan 2 buah net (200\%) dengan kategori baik, SDN Sungai Batang 1 tidak memiliki (0\%) dan SDN Melayu Tengah memiliki $1(100 \%)$ dengan kategori baik. Tersedianya net bulu tangkis SDN Keramat dengan 2 buah net (200\%) dengan kategori baik, SDN Sungai Batang 1 dan SDN Melayu Tengah tidak memiliki (0\%).

Tersedianya tiang net bola voli SDN Keramat dengan 2 buah tiang net (100\%) dengan kategori baik, SDN Sungai Batang 1 dan SDN Melayu Tengah tidak memiliki $(0 \%)$. tersedinya gawang sepak bola di SDN Keramat, SDNSungai Batang 1 dan SDN Tengah tidak memiliki gawang $(0 \%)$. Untuk tersedianya ring basket di SDN Keramat, SDN Sungai Batang 1 dan SDN Melayu Tengah tidak memiliki ring basket (0\%). Untuk tersedianya alat pemukul kasti di SDN Keramat dengan 2 buah $(33,33 \%)$ berkategori baik, SDN Sungai Batang 1 dan SDN Melayu Tengah tidak memiliki (0\%).

Kalau untuk tersedianya alat pembelajaran atletik start blok di SDN Keramat dengan 6 buah (100\%) dengan kategori baik, SDN Sungai Batang 1 dan SDN Melayu Tengah tidak memiliki $(0 \%)$. Kalau tersedianya alat pembelajaran atletik POA (perlengkapan olahraga anak) di SDN Keramat dengan 1 set (100\%) dengan kategori baik, SDN Sungai Batang 1 dan SDN Melayu Tengah tidak memiliki (0\%).

Untuk tersedianya alat pembelajaran senam tongkat di SDN Keramat dengan 10 buah $(166,67 \%)$ berkategori baik, SDN Sungai Batang 1 dan SDN Melayu Tengah tidak memiliki (0\%). tersedianya alat pembelajaran senam matras di SDN Keramat dengan 2 buah (100\%) berkategori baik, SDN Sungai Batang 1 dan SDN Melayu Tengah tidak memiliki $(0 \%)$. Tersedianya alat pembelajaran senam tape recorder di SDN Keramat dengan 1 buah (100\%) berkategori baik, SDN Sungai Batang 1 tidak memiliki (0\%) dan SDN Melayu Tengah 1 buah memiliki (100\%).

Tabel 2. Hasil Tersedia Sarana dan Prasarana

\begin{tabular}{|c|c|c|c|}
\hline \multirow{2}{*}{ Kategori } & \multicolumn{3}{|c|}{ Nama Sekolah } \\
\cline { 2 - 4 } & SDN Keramat & $\begin{array}{l}\text { SDN Sungai } \\
\text { Batang 1 }\end{array}$ & $\begin{array}{l}\text { SDN } \\
\text { Melayu } \\
\text { Tengah }\end{array}$ \\
\hline Baik & $11(34 \%)$ & $1(3 \%)$ & $2(6 \%)$ \\
\hline Cukup & $2(6 \%)$ & $1(3 \%)$ & 0 \\
\hline Kurang & $19(59 \%)$ & $30(94 \%)$ & $30(94 \%)$ \\
\hline
\end{tabular}

Keterbatasan sarana prasarana dikarenakan ada suatu penunjang kegiatan belajar yang lebih memprioritaskan penataan keindahan lingkungan sekolah dengan melakukan 
kegiatan penghijauan lingkungan sebagai nilai tambah pada saat akreditasi sekolah dan kekurangan sarana prasarana juga disebabkan kurang mampunya pihak sekolah menganggarkan dana pengadaan peralatan penunjang kegiatan pembelajaran pendidikan jasmani dan olahraga serta keterbatasan dana anggaran yg dimiliki sekolah karena masih ada mata pelajaran lainnya yang sarana prasarana harus dipenuhi.

Keterbatasan sarana prasarana juga suatu penunjang dalam proses belajarnya seorang guru yang profesional dalam membuat suatu pembelajaran yang unik, kreatif, dan juga inovatif, maka dari itulah seorang guru harus menggunakan media alat bantu agar suatu proses belajar bisa terlaksana dengan baik baik menggunakan ranting pohon atau dengan batu-batu yang ada agar anak didik senang dan tidak mudah bosan dalam pembelajaran tersebut agar tercapai apa yang diinginkan.

\section{KESIMPULAN}

Dari penelitian tersebut dapat kita ambil suatu kesimpulan dari penelitian ini yaitu tingkat kesegaran jasmani peserta didik usia $10-12$ tahun dan tersedianya sarana prasarana penunjang pembelajaran penjas dan olahraga di Sekolah Dasar Negeri di Martapura Kabupaten Banjar adalah sebagai berikut :

1. SDN Keramat Martapura Kabupaten Banjar

Tingkat kesegaran jasmani, klasifikasi yang sedang terdapat 2 orang, untuk klasifikasi kurang yaitu 9 orang dan untuk klasifikasi kurang sekali yaitu 6 orang. Dalam tersedianya sarana prasarana berkategori baik 11, kategori cukup 2 dan kategori kurang 19.

2. SDN Sungai Batang 1 Martapura Kabupaten Banjar

Tingkat kesegaran jasmani, untuk klasifikasi sedang 1 orang, untuk klasifikasi kurang 2 orang dan untuk klasifikasi kurang sekali 3 orang. Dalam tersedianya sarana prasarana berkategori baik 1, kategori cukup 1 dan kategori kurang 30.

3. SDN Melayu Tengah Martapura Kabupaten Banjar

Tingkat kesegaran jasmani, untuk klasifikasi sedang 1 orang, untuk klasifikasi kurang 5 orang dan untuk klasifikasi kurang sekali 3 orang. Dalam terbatasnya sarana prasarana yang berkategori baik 2, kategori cukup 0 dan kategori kurang 30 .

\section{SARAN}

Saran untuk penelitian ini ialah kepada peserta didik itu sendiri yang harus membiasakan dalam menghadapi masalah gerak, contohnya jangan terlalu sering nonton tv setelah selesai dan juga jangan terlalu bermain game karna akan mengakibatkan kesegaran jasmani berkurang ataupun menurun. Untuk saran selanjutnya kepada kepala sekolah agar dapat menyediakan sarana prasarana yang pas buat pembelajaran disekolah setidaknya dengan memberikan fasilitas olahraga yang lengkap misal dari bola-bola untuk bermain kelincahan seorang anak didik dan juga lapangan yang khusus buat berolahraga. Kemudian untuk saran kepada guru-guru penjas agar dapat menyelesaikan masalah tersebut dengan cara melakukan atau memanfaatkan alat ataupun benda yang ada disekitar sekolah biar menjadi bahan untuk pembelajaran biar anak didik selalu bergerak aktif dalam mengikutinya.

\section{DAFTAR PUSTAKA}

Agus S. Suryobroto. (2004). Diklat Sarana Prasarana Tentang Pendidikan Jamani. Yogyakarta: FIK UNY. 
Depdiknas. 2003. Perundangan RI No.20 tahun 2003 dalam proses pendidikan nasional.

Djoko Pekik I. (2004). Pedoman Praktis Berolahraga Untuk Kebugaran dan Kesehatan. Yogyakarta:PT Andi Offset.

Eko Susilo. (2007). Keadaan Sarana dan Prasarana Pendidikan Jasmani di SMA Negeri se-Kabupaten Wonosobo. Yogyakarta: FIK UNY.

Nurhasan. 2011. Tips Praktis Menjaga Kebugaran Jasmani. Gresik Jawa Timur: Abil Pustaka

Ponijah. (2014). Survai Tingkat Kesegaran Jasmani Siswa Kelas II dan III SD Negeri Godean 2 Kecamatan Godean Kabupaten Sleman Daerah Istimewa Yogyakarta. Skripsi. Yogyakarta: FIK-UNY

Ristyanto, Wahyu. 2017. Survei Sarana Dan Prasarana Pendidikan Jasmani Sekolah Menengah Kejuruan Se-Kecamatan Wonosari Kabupaten Gunungkidul. Skripsi. Jurusan Pendidikan Olahraga FIK UNY.

Soepartono. (2000). Sarana dan Prasarana Olahraga. Jakarta : Departemen Pendidikan Nasional.

Sudijino, Anas. 2011. Pengantar Statistik Pendidikan. Jakarta: PT Raja Grafindo Persada.

Sugiyono. 2015. Metode Penelitian \& Pengembangan Research And Development. Bandung. Alfabeta.

Tim Revisi JPOK FKIP ULM. 2014. Pedoman Penulisan Karya Ilmiah. Banjarbaru: JPOK FKIP Unlam Banjarbaru Kalimantan Selatan.

Widiastuti. 2015. Tes Dan Pengukuran Olahraga. Jakarta: PT. RajaGrafindo Persada. 